\title{
An Improved Detached-Leaf Assay for Phenotyping Net Blotch of Barley Caused by Pyrenophora teres
}

I. M. El-Mor, University of Southern Queensland, Centre for Crop Health, Toowoomba, 4350, QLD, Australia; R. A. Fowler and G. J. Platz, Queensland Department of Agriculture \& Fisheries, Hermitage Research Facility, Warwick, 4370, QLD, Australia; and M. W. Sutherland and A. Martin, ${ }^{\dagger}$ University of Southern Queensland, Centre for Crop Health, Toowoomba

\begin{abstract}
Net blotch, caused by Pyrenophora teres, is a major barley (Hordeum vulgare) leaf disease worldwide. P. teres occurs as two forms-P. teres f. teres, and $P$. teres f. maculata-inducing net and spot-like symptoms, respectively. An intact-seedling assay, where entire seedlings are inoculated by spraying with a conidial suspension, is frequently used for phenotyping net blotch. However, this presents a biosecurity risk in the glasshouse when nonlocal isolates are being screened. Alternatively, a detached-leaf assay (DLA-droplet method) can be used in which leaf segments laid out in a covered tray are inoculated with droplets of a conidial

suspension, confining the inoculum. However, using this method, net and spot form symptoms cannot be distinguished from each other. We have developed an improved DLA (DLA-spray method) in which detached whole leaves are sprayed with the inoculum to produce distinct lesions. We compare the results for the three phenotyping methods above using four isolates from both net and spot forms of the disease to inoculate a standard set of eight barley genotypes. Results indicate that the DLA-spray method is a functional, informative and rapid test that readily differentiates the two forms of the pathogen in a biosecure environment.
\end{abstract}

Net blotch is a major barley (Hordeum vulgare L.) foliar disease that is estimated to cost Australian agriculture $\$ 60$ million per year and potentially over $\$ 300$ million in a high disease year (Murray and Brennan 2009). Economic loss is not exclusively due to yield loss but is also due to the degradation of seed quality due to the reduction of grain size resulting from lower carbohydrate content of grain (Shipton 1966). Furthermore, heavy early infection can reduce ear number (SmedegårdPetersen 1974) and the number of grains per ear (Jordan et al. 1985).

Net blotch is expressed first as small circular or elliptical lesions that develop into large dark-brown blotches; development of these blotches differs according to the host genotype, pathogen virulence, and environmental conditions (Liu et al. 2011). In susceptible barley genotypes, necrotic lesions are produced followed by a halo of chlorosis (Scott 1991; Steffenson and Webster 1992). With severe infections, whole leaves have a brown senescent appearance due to complete necrosis of entire leaves and this may lead to death of the plant (Mathre 1997; Schaller 1955).

Net blotch can survive on seed and infected stubble (Bretag 2009; Shipton et al. 1973; van den Berg and Rossnagel 1991), and can occur wherever barley is cultivated (McLean et al. 2009; Steffenson and Webster 1992; van den Berg and Rossnagel 1991). However, severe infections are more common in temperate regions with high rainfall and humidity (Bretag 2009; Steffenson and Webster 1992; Weiland et al. 1999).

Pyrenophora teres Drechslera (anamorph: Drechslera teres (Sacc.) Shoemaker) is the fungal pathogen that causes net blotch disease in barley (McDonald 1963). P. teres occurs as two forms that are distinguished according to the symptoms they express on the host rather than their morphology. Even though the initial symptoms of both forms are similar, the mature symptoms are typically distinct (Sarpeleh et al. 2007). Net form of net blotch (NFNB), caused by $P$. teres $\mathrm{f}$. teres, produces elongated light-brown stripes or lesions on leaves and leaf sheaths of older plants and gives a characteristic netting pattern in juvenile leaves, with dark-brown necrotic reticulations. Spot form of net blotch (SFNB), caused by P. teres f. maculata, produces dark-brown, round to elliptical spots on leaves and leaf

${ }^{\dagger}$ Corresponding author: A. Martin; E-mail: anke.martin@usq.edu.au

Accepted for publication 31 October 2017.

(c) 2018 The American Phytopathological Society sheaths that are often surrounded by yellowing or distinct chlorotic areas (Campbell et al. 1999; Rau et al. 2007).

$P$. teres is a highly diverse heterothallic haploid fungus (Shipton et al. 1973). This diversity makes it challenging to develop efficient and long-lasting resistance in the host because many of the progeny resulting from sexual reproduction induce host responses that differ from the host responses to the parents (Weiland et al. 1999). Although rare, sexual reproduction has been observed between the two forms of P. teres (Campbell et al. 2002; McLean et al. 2014). The progeny of these recombinants have been referred to as hybrids. Hybrids have also been successfully produced in laboratory culture (Campbell et al. 1999; Poudel et al. 2017). The intact-seedling assay is currently the standard method for phenotyping net blotch of barley (Arabi et al. 1991; Sharma 1984; Xi et al. 1999). However, when studying laboratory-produced $P$. teres hybrids with potentially new virulences, it is crucial to confine the pathogen. A previously published detachedleaf assay (DLA)-droplet method confines the isolates within trays (Afanasenko et al. 2007). Thus, it is suitable for screening recombinants of $P$. teres. However, it is difficult to determine whether an isolate has the typical net-form or spot-form lesions using this method. Therefore, the aim of this study was to develop an improved method that still confines the isolates but produces infection responses similar to those obtained with the intact-seedling assay. To achieve this, the DLA-droplet method was modified to a spray method, where whole leaves replaced the leaf segments to provide greater leaf surface area for even dispersal of inoculum, which produces clear disease symptoms. This allows the development of discrete lesions arising from a single spore. The improved method was compared with both the DLA-droplet method and the intact-seedling assay.

\section{Materials and Methods}

Plant and fungal material. Two NFNB isolates (NB053 and NB085) and two SFNB isolates (SNB171 and SNB74) from the Lehmensiek et al. (2010) study were used to compare the different phenotyping methods. These isolates were screened across eight barley genotypes: NRB11313, Clho 5791, Skipper, Skiff, Prior, Keel, Dash, and Westminster. Each of the three methods was repeated four times.

Seedling production. For the intact-seedling assay, seed of the eight genotypes were planted in separate pots, $50 \mathrm{~mm}^{2}$ by $120 \mathrm{~mm}$ deep (five seeds per pot), containing Searles Premium potting mix (JC \& AT Searle Pty. Ltd.). Pots were placed randomly in trays in the glasshouse with day and night temperatures of approximately 24 and $20^{\circ} \mathrm{C}$, respectively, for 19 days prior to inoculation. For both DLA, 20 seeds of each genotype were planted in a 100-mm-diameter pot and placed randomly 
in trays in the glasshouse 19 days prior to inoculation. Once germinated, all plants were fertilized fortnightly using Yates Thrive (Dulux Group Pty. Ltd.) (nitrogen/phosphorus ratio $=5: 1$ ).

Single-conidial isolates. The four isolates (NB053, NB085, SNB171, and SNB74) were collected from infected dry barley leaf pieces. Each leaf piece was immersed in $70 \%$ ethanol for $5 \mathrm{~s}$, then
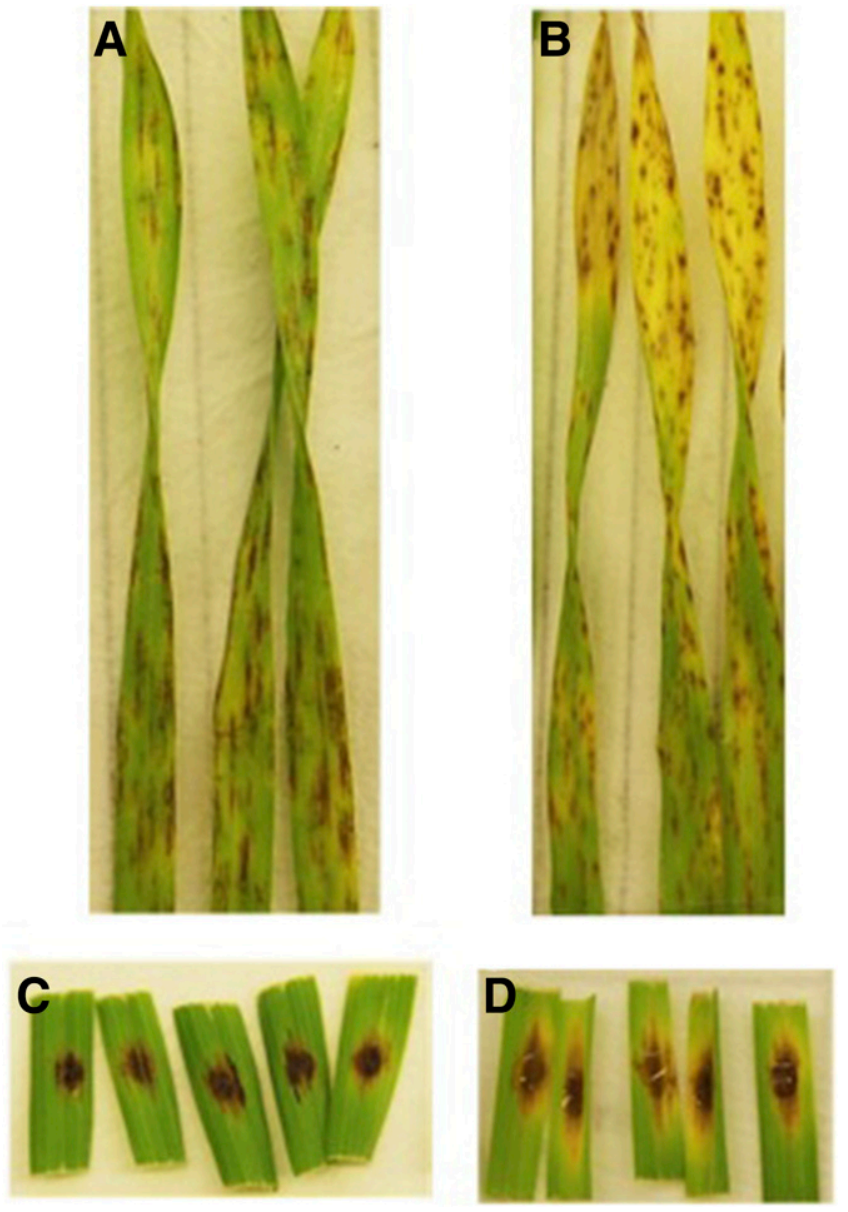

Fig. 1. Barley inoculated with $A$, net form of net blotch (NFNB) isolate using detachedleaf assay (DLA)-spray method; $B$, spot form of net blotch (SFNB) isolate using DLAspray method; C, NFNB isolate using DLA-droplet method; and D, SFNB isolate using DLA-droplet method. washed for $2 \mathrm{~min}$ in $5 \%$ sodium hypochlorite $(\mathrm{NaOCl})$, followed by three rinses in distilled water. Each leaf piece was placed on a filter paper saturated with distilled water in a Petri dish and incubated under natural light at room temperature (Lehmensiek et al. 2010). Leaves were monitored daily for appearance of conidia and, once conidia were observed, a single conidium was picked using a sterile needle and plated onto potato dextrose agar (PDA) plates. The plates were incubated at $22^{\circ} \mathrm{C}$ with a 12-h photoperiod for 5 days to obtain mycelial cultures.

Inoculum preparation. Conidia were cultured by placing five plugs of each mycelial culture on the margins of sterilized barley or wheat leaf segments on $2 \%$ water agar medium for 10 days prior to inoculation (Deadman and Cooke 1985; Ismail et al. 2014). These were placed on the windowsill in the laboratory at $22^{\circ} \mathrm{C}$ under natural daylight conditions. To remove the conidia, each plate was rinsed with $10 \mathrm{ml}$ of distilled water and conidia were dislodged with a sterile paintbrush. This suspension was filtered through a fine sieve into a flask. The conidia were quantified using a hemocytometer (Weber and Sons) and the suspension adjusted to a concentration of 5,000 conidia/ml. Three drops of Tween 20 solution were added to each suspension in a final volume of $20 \mathrm{ml}$. Conidial suspensions were stored for a maximum of two months at $-70^{\circ} \mathrm{C}$ before inoculation (Knight and Sutherland 2013). All repeat experiments of the intact-seedling assays and both DLA methods used the same stock of conidial suspension generated for each isolate.

Tray preparation. The DLA-droplet assay is based on the method described by Afanasenko et al. (2007). Fully expanded second leaves were cut into 3-cm-long segments and five segments of each barley genotype were placed into 15-cm-diameter Petri dishes on two sheets of sterilized filter paper moistened with $10 \mathrm{ml}$ of sterile water containing $0.004 \%$ benzimidazole. The leaf segments were arranged into groups, with the adaxial side of the leaf uppermost.

For the DLA-spray method, three whole second leaves of each of the eight barley genotypes were taped in groups of three onto square 22.5-by-22.5-cm Petri dishes (Thermofisher) with the adaxial side of the leaf uppermost. Each tray contained one layer of Amersham Hybond blotting paper (GE Healthcare Life Sciences) moistened with $35 \mathrm{ml}$ of sterile water containing $0.004 \%$ benzimidazole. Phenotyping of each isolate on the eight genotypes was repeated four times for both of the DLA methods and the seedling assay. Genotypes and trays were randomly assigned to positions in the incubator and glasshouse.

Inoculations. Intact-seedling assay inoculations used $20 \mathrm{ml}$ of conidial suspension, which was inoculated onto seedlings using a Preval spray gun (Sedl Agencies). The pots were then randomly arranged in a humidity chamber for an incubation period of $24 \mathrm{~h}$ at $99 \%$ relative humidity and a temperature of $23^{\circ} \mathrm{C}$. Pots were then moved to a glasshouse with day and night temperatures of approximately 24 and $20^{\circ} \mathrm{C}$, respectively, for 14 days before rating disease response.

Table 1. Mean disease responses of eight barley genotypes to four Pyrenophora teres isolates and three phenotyping methods ${ }^{\mathrm{a}}$

\begin{tabular}{|c|c|c|c|c|c|c|c|c|}
\hline \multirow[b]{2}{*}{ Method, isolate } & \multicolumn{8}{|c|}{ Disease response (standard error) per host genotype } \\
\hline & Clho 5791 & Dash & Keel & NRB11313 & Prior & Skiff & Skipper & Westminster \\
\hline \multicolumn{9}{|l|}{ Seedling assay } \\
\hline NB053 & $2.4(0.13)$ & $4.5(0.30)$ & $4.8(0.23)$ & $3.0(0.21)$ & $4.2(0.23)$ & $4.5(0.32)$ & $4.9(0.24)$ & $4.5(0.20)$ \\
\hline NB085 & $4.3(0.23)$ & $7.9(0.22)$ & $7.4(0.44)$ & $3.9(0.25)$ & $9.0(0.05)$ & $6.6(0.28)$ & $5.9(0.23)$ & $6.9(0.21)$ \\
\hline SNB171 & $2.4(0.17)$ & $5.3(0.30)$ & $3.3(0.23)$ & $2.6(0.28)$ & $4.2(0.37)$ & $3.0(0.28)$ & $2.4(0.22)$ & $4.1(0.34)$ \\
\hline SNB74S & $3.1(0.27)$ & $5.8(0.45)$ & $3.5(0.11)$ & $2.9(0.25)$ & $4.2(0.41)$ & $2.9(0.22)$ & $3.3(0.22)$ & $4.5(0.49)$ \\
\hline \multicolumn{9}{|l|}{ DLA-droplet } \\
\hline NB053 & $2.7(0.11)$ & $3.0(0.25)$ & $3.0(0.35)$ & $2.6(0.20)$ & $2.8(0.19)$ & $3.4(0.34)$ & $2.8(0.23)$ & $3.3(0.40)$ \\
\hline NB085 & $2.8(0.10)$ & $4.5(0.35)$ & $5.7(0.45)$ & $3.0(0.07)$ & $6.2(0.39)$ & $4.6(0.41)$ & $3.1(0.17)$ & $4.4(0.36)$ \\
\hline SNB171 & $2.7(0.11)$ & $2.9(0.14)$ & $2.8(0.28)$ & $2.5(0.14)$ & $3.0(0.20)$ & $2.2(0.17)$ & $2.5(0.17)$ & $2.7(0.17)$ \\
\hline SNB74S & $2.1(0.19)$ & $2.7(0.18)$ & $2.3(0.23)$ & $2.2(0.17)$ & $2.6(0.21)$ & $1.5(0.23)$ & $2.5(0.22)$ & $2.0(0.21)$ \\
\hline \multicolumn{9}{|l|}{ DLA-spray } \\
\hline NB053 & $2.4(0.15)$ & $4.7(0.43)$ & $5.6(0.38)$ & $3.0(0.00)$ & $3.8(0.17)$ & $4.8(0.39)$ & $4.7(0.47)$ & $4.3(0.52)$ \\
\hline NB085 & $4.7(0.14)$ & $9.0(0.00)$ & $8.5(0.26)$ & $4.3(0.15)$ & $9.3(0.13)$ & $6.7(0.14)$ & $7.3(0.28)$ & 7.7 (0.19) \\
\hline SNB171 & $2.8(0.13)$ & $5.7(0.43)$ & $2.8(0.30)$ & $2.4(0.31)$ & $4.7(0.61)$ & $2.7(0.19)$ & $2.5(0.19)$ & $5.4(0.23)$ \\
\hline SNB74S & $2.8(0.35)$ & $5.2(0.59)$ & $2.7(0.22)$ & $2.5(0.26)$ & $3.5(0.48)$ & $2.1(0.26)$ & $2.3(0.22)$ & $4.3(0.59)$ \\
\hline
\end{tabular}

${ }^{\text {a }}$ Scores of 0.0 to 3.5 indicate resistance, 3.6 to 6.5 indicate intermediate response (moderate resistance to moderate susceptibility) (in italics), and 6.6 to 10.0 indicate susceptibility (in bold). Each score represents the mean of four independent experiments, each of which included five replicates for the detached-leaf assay (DLA)-drop method and three replicates each for the seedling assay and DLA-spray method. 
The DLA-droplet method used a droplet volume of $10 \mu$ l of conidial suspension, which was placed in the center of each leaf segment (Fig. $1 \mathrm{C}$ and D). The DLA-spray method used $10 \mathrm{ml}$ of conidial solution per tray, which was inoculated evenly onto the leaves using a Preval spray gun (Sedl Agencies) (Fig. 1A and B). Trays were sealed inside clear plastic bags to maintain high humidity, then placed in an incubator at an average temperature of $20 \pm 5^{\circ} \mathrm{C}$ with a 12 -h photoperiod for 6 days.

Disease rating. Disease scores were recorded 14 days after inoculation of the intact seedlings and 6 days after inoculation for both DLA methods. For rating the three assays, the Tekauz (1985) seedling rating scales were used, with modifications. According to Tekauz (1985), a score of 1.0 is highly resistant, and 9.0 and 10.0 are highly susceptible for SFNB and NFNB, respectively. The modified rating scale used in this study has three groupings, where 0.0 to 3.5 was considered resistant, 3.6 to 6.5 was considered intermediate, and higher than 6.6 was considered susceptible.

Data analysis. Spearman's rank correlation coefficient analysis was performed using Microsoft Excel to test the hypotheses that the DLA-spray method can replace both the intact-seedling assay and the DLA-droplet method for disease phenotyping by identifying and testing the strength of the relationship between the three sets of data.

To evaluate both of the DLA methods in comparison with the intactseedling assay, we produced a contingency table (Kanchanaraksa 2008; Kattan and Cowen 2009; Shaikh 2012), with the intact-seedling assay chosen as the gold standard test to determine the specificity and sensitivity of each of the DLA methods. In this test, the sensitivity expresses "the ability of the test to correctly identify the disease" (susceptibility) (Kanchanaraksa 2008), whereas specificity is "the ability of the test to correctly identify those which do not have the disease" (resistance) (Kanchanaraksa 2008). Due to the nature of the contingency test, we only used the reactions falling into the resistant ( 0.0 to 3.5$)$ and susceptible (6.6 to 10.0) groupings.

\section{Results}

The results of the intact-seedling assays (Table 1) revealed a range of host responses to the four pathogen isolates tested. NFNB isolate NB085 was the most virulent, with only the NRB11313, Clho 5791, and Skipper barley genotypes expressing intermediate responses to this isolate. The two NFNB isolates generally showed higher virulence on this particular set of barley genotypes than the two SFNB isolates. Net-form and spot-form symptoms were clearly distinguishable using either the intact-seedling assay or the DLA-spray method (Fig. 1A and B) but could not be distinguished using the DLAdroplet method (Fig. 1C and D).

Overall correlations between the three methods were higher in each comparison for the NFNB than the SFNB isolates. The highest correlation was observed between the DLA-spray method and the intact-seedling assay (0.92 to 0.97 ) (Table 2).

For the contingency test, only the results for the NFNB are shown due to resistance of most of the genotypes to the SFNB isolates. Of the 16 grand means of the responses between the two NFNB isolates and the eight genotypes, the intact-seedling assay indicated the susceptibility of 5 samples and resistance of 2 . The DLA-droplet method (Table 3) indicated susceptibility of none of the screened isolates or genotypes out of those five, whereas the DLA-spray method (Table 4) indicated six susceptible responses. The DLA-droplet method showed 11 resistant responses out of the 16 while the DLA-spray method indicated 2 resistant responses. By calculating the sensitivity (ability to identify susceptible genotypes) and specificity (ability to detect resistant genotypes), the DLA-droplet method exhibited $0.0 \%$ sensitivity

Table 2. Correlations between the three methods (intact-seedling assay, detached-leaf assay (DLA)-spray, and DLA-droplet) for each of the four isolates screened: NB053, NB085, SNB171, and SNBS74

\begin{tabular}{lcccc}
\hline Method & NB053 & NB085 & SNB171 & SNBS74 \\
\hline Seedling and DLA-spray & 0.93 & 0.97 & 0.92 & 0.97 \\
DLA-spray and DLA-droplet & 0.57 & 0.81 & 0.64 & 0.48 \\
Seedling and DLA-droplet & 0.57 & 0.90 & 0.67 & 0.57 \\
\hline
\end{tabular}

and $100 \%$ specificity. The DLA-spray test, however, showed $100 \%$ sensitivity and $66.7 \%$ specificity.

\section{Discussion}

This study describes and evaluates an improved phenotyping method for net blotch diseases of barley. The new technique is a detached-leaf technique that confines novel fungal isolates in the laboratory and produces clear differentiation between the net and spot forms of net blotch, in contrast to the DLA-droplet method currently used. The spray method provides an efficient solution for researchers looking to conduct phenotyping experiments that reduce the risk of novel pathogen isolates escaping from containment while maintaining high sensitivity and specificity. There is also no need for a humidity chamber because plates are incubated in sealed bags in an incubator.

The weaker correlations between the DLA-droplet method and the DLA-spray method and between the DLA-droplet method and the intact-seedling assay might be due to the nature of the inoculum employed. Unlike the DLA-spray method and the intact-seedling assay, the DLA-droplet method uses small segments of leaves that are inoculated with a single drop of the conidial suspension. This concentrates a high number of infection sites within a localized area, blurring the lesion patterns arising from each site; whereas, in the other two methods, the seedling and DLA-spray methods distribute the inoculum evenly but less densely across the leaf's surface, allowing numerous individual infection sites to develop and exhibit their characteristic growth patterns.

The highly significant correlation between the intact-seedling assay and the DLA-spray method indicates the high reliability of the DLA-spray method. The overall ratings in the DLA-droplet method were generally lower than the DLA-spray method and the intactseedling assay ratings, providing a higher level of false positives when attempting to identify resistant host genotypes. This was clearly demonstrated by the contingency test (Table 3), where the DLAdroplet method failed to express the susceptibility of any of the five

Table 3. Contingency table representing the gold standard test to evaluate specificity and sensitivity of detached-leaf assay (DLA)-droplet method compared with the intact-seedling assay for net form of net blotch (NFNB)

\begin{tabular}{lll}
\hline & \multicolumn{2}{c}{ Seedling assay results } \\
\cline { 2 - 3 } DLA-droplet test (NFNB) & \multicolumn{1}{c}{ Susceptible (+ve) } & \multicolumn{1}{c}{ Resistant $(-\mathbf{v e})$} \\
\hline $\begin{array}{c}\text { Test results susceptible } \\
(+\mathrm{ve}) \text { MS-S }\end{array}$ & True positive $(\mathrm{TP})=0$ & False positive $(\mathrm{FP})=0$ \\
$\begin{array}{c}\text { Test results resistant } \\
(-\mathrm{ve}) \mathrm{R}-\mathrm{MR}\end{array}$ & False negative $(\mathrm{FN})=9$ & True negative $(\mathrm{TN})=2$ \\
& & \\
& Sensitivity & Specificity \\
& $=\mathrm{TP} /(\mathrm{TP}+\mathrm{FN})$ & $=\mathrm{TN} /(\mathrm{FP}+\mathrm{TN})$ \\
& $=0 /(0+9)$ & $=2 /(0+2)$ \\
& $=0 \%$ & $=100 \%$ \\
\hline
\end{tabular}

${ }^{a} \mathrm{MS}=$ moderately susceptible, $\mathrm{S}=$ susceptible, $\mathrm{R}=$ resistant, and $\mathrm{MR}=$ moderately resistant.

Table 4. Contingency table representing the gold standard test to evaluate specificity and sensitivity of detached-leaf assay (DLA)-spray method compared with the intact-seedling assay for net form of net blotch (NFNB)

\begin{tabular}{lll}
\hline & \multicolumn{2}{c}{ Seedling assay results } \\
\cline { 2 - 3 } DLA-spray test (NFNB) & \multicolumn{1}{c}{ Susceptible (+ve) } & \multicolumn{1}{c}{ Resistant (-ve) } \\
\hline $\begin{array}{c}\text { Test results susceptible } \\
(+\mathrm{ve}) \text { MS-S }\end{array}$ & True positive (TP) $=5$ & False positive $(\mathrm{FP})=1$ \\
$\begin{array}{c}\text { Test results resistant } \\
(-\mathrm{ve}) \mathrm{R}-\mathrm{MR}\end{array}$ & False negative $(\mathrm{FN})=0$ & True negative $(\mathrm{TN})=2$ \\
& Sensitivity & Specificity \\
& $=\mathrm{TP} /(\mathrm{TP}+\mathrm{FN})$ & $=\mathrm{TN} /(\mathrm{FP}+\mathrm{TN})$ \\
& $=5 /(5+0)$ & $=2 /(1+2)$ \\
& $=100 \%$ & $=66.7 \%$ \\
\hline
\end{tabular}

${ }^{\mathrm{a}} \mathrm{MS}=$ moderately susceptible, $\mathrm{S}=$ susceptible, $\mathrm{R}=$ resistant, and $\mathrm{MR}=$ moderately resistant. 
susceptible samples. By comparison, the DLA-spray method (Table 4) indicated six susceptible responses, with only one of them being a false susceptible in comparison with the intact-seedling assay.

The DLA-spray method allows for symptoms of both forms of $P$. teres to be clearly distinguished. Both the net reticulations and elliptical spots for NFNB (Fig. 1A) and SFNB (Fig. 1B), respectively, were clearly identified by the DLA-spray method in contrast to the DLA-droplet method (Fig. 1C and D). Thus, the DLA-spray method will be useful for determining the virulence and lesion types of laboratory-generated hybrid forms (Poudel et al. 2017) while keeping the isolates confined in a laboratory biosafety cabinet.

In a study by Kumar et al. (2011), the DLA-droplet method was used to screen Fusarium head blight partial disease resistance in barley. The authors concluded that the DLA-droplet method could be used for prescreening of a wide range of genotypes However, in comparison with Fusarium graminearum, the DLA-droplet method failed to produce susceptible reactions following inoculation with $F$. culmorum, indicating the tendency of this method to provide false positives for resistance in some interactions (Kumar et al. 2011). Similarly, upon evaluating resistance in wheat against five different species $(F$. culmorum, $F$. graminearum, $F$. avenaceum, $F$. poae, and Microdochium nivale var. majus and var. nivale), Browne and Cooke (2005) observed that some wheat genotypes displayed moderate susceptibility with an intact-seedling assay but displayed moderate resistance using the DLA-droplet method.

Although the development of the of the DLA-droplet method (Afanasenko et al. 2007) has provided a useful advance in phenotyping foliar diseases, this current study indicates that modifications involving the use of a spray inoculum significantly improve the correlation with results from intact barley seedling screens of reactions to net blotch isolates. The spray inoculum also differentiates clearly between net-form and spot-form lesion types.

\section{Acknowledgments}

We thank the Grains Research and Development Corporation of Australia for support of this research and the statisticians at Leslie Research Facility, Toowoomba for the experimental design they provided.

\section{Literature Cited}

Afanasenko, O., Mironenko, N., Filatova, O., Kopahnke, D., Krämer, I., and Ordon, F. 2007. Genetics of host-pathogen interactions in the Pyrenophora teres f. teres (net form)-barley (Hordeum vulgare) pathosystem. Eur. J. Plant Pathol. 117:267-280.

Arabi, M. I., Sarrafi, A., Barrault, G., and Albertini, L. 1991. An improved technique for determining net blotch resistance in barley. Plant Dis. 75:703-706.

Bretag, T. 2009. Threat Specific Contingency Plan: Net Form of Net Blotch (Exotic Pathotypes) Pyrenophora teres f. sp. teres. Plant Health Australia, Canberra, ACT, Australia.

Browne, R. A., and Cooke, B. M. 2005. Resistance of wheat to Fusarium spp. in an in vitro seed germination assay and preliminary investigations into the relationship with Fusarium head blight resistance. Euphytica 141:23-32.

Campbell, G. F., Crous, P. W., and Lucas, J. A. 1999. Pyrenophora teres f. maculata, the cause of Pyrenophora leaf spot of barley in South Africa. Mycol. Res. 103:257-267.

Campbell, G. F., Lucas, J. A., and Crous, P. W. 2002. Evidence of recombination between net- and spot-type populations of Pyrenophora teres as determined by RAPD analysis. Mycol. Res. 106:602-608.

Deadman, M., and Cooke, B. 1985. A method of spore production for Drechslera teres using detached barley leaves. Trans. Br. Mycol. Soc. 85:489-493.

Ismail, I. A., Godfrey, D., and Able, A. J. 2014. Fungal growth, proteinaceous toxins and virulence of Pyrenophora teres f. teres on barley. Australas. Plant Pathol. 43:535-546.

Jordan, V. W. L., Best, G. R., and Allen, E. C. 1985. Effects of Pyrenophora teres on dry matter production and yield components of winter barley. Plant Pathol. 34:200-206.
Kanchanaraksa, S. 2008. Evaluation of Diagnostic and Screening Tests: Validity and Reliability. John Hopkins University, Bloomberg School of Public Health, Baltimore, MD.

Kattan, M. W., and Cowen, M. E. 2009. Encyclopedia of Medical Decision Making. Sage Publications Inc., Thousand Oaks, CA.

Knight, N. L., and Sutherland, M. W. 2013. Histopathological assessment of whea seedling tissues infected by Fusarium pseudograminearum. Plant Pathol. 62: 679-687.

Kumar, K., Xi, K., Turkington, T. K., Tekauz, A., Helm, J. H., and Tewari, J. P. 2011. Evaluation of a detached leaf assay to measure Fusarium head blight resistance components in barley. Can. J. Plant Pathol. 33:364-374.

Lehmensiek, A. M., Bester-van der Merwe, A. E., Sutherland, M. W., Platz, G. J., Krield, W. M., Potgietere, G. F., and Prins, R. 2010. Population structure of South African and Australian Pyrenophora teres isolates. Plant Pathol. 59: 504-515.

Liu, Z. W., Ellwood, S. R., Oliver, R. P., and Friesen, T. L. 2011. Pyrenophora teres: Profile of an increasingly damaging barley pathogen. Mol. Plant Pathol. 12:1-19.

Mathre, D. E. 1997. Compendium of Barley Diseases. American Phytopathological Society Press, St. Paul, MN.

McDonald, W. C. 1963. Heterothallism in Pyrenophora teres. Phytopathology 53 771-773.

McLean, M. S., Howlett, B. J., and Hollaway, G. J. 2009. Epidemiology and control of spot form of net blotch (Pyrenophora teres f. maculata) of barley: A review. Crop Pasture Sci. 60:303-315.

McLean, M. S., Martin, A., Gupta, S., Sutherland, M. W., Hollaway, G. J., and Platz, G. J. 2014. Validation of a new spot form of net blotch differential set and evidence for hybridisation between the spot and net forms of net blotch in Australia. Australas. Plant Pathol. 43:223-233.

Murray, G. M., and Brennan, J. P. 2009. The Current and Potential Costs from Diseases of Barley in Australia. Grains Research and Development Corporation, Canberra, ACT Australia.

Poudel, B., Ellwood, S. R., Testa, A. C., McLean, M., Sutherland, M. W., and Martin, A. 2017. Rare Pyrenophora teres hybridization events revealed by development of sequence-specific PCR markers. Phytopathology 107:878-884.

Rau, D., Attene, G., Brown, A. H., Nanni, L., Maier, F. J., Balmas, V., Saba, E., Schafer, W., and Papa, R. 2007. Phylogeny and evolution of mating-type genes from Pyrenophora teres, the causal agent of barley "net blotch" disease. Curr. Genet. 51:377-392

Sarpeleh, A., Wallwork, H., Catcheside, D. E., Tate, M. E., and Able, A. J. 2007 Proteinaceous metabolites from Pyrenophora teres contribute to symptom development of barley net blotch. Phytopathology 97:907-915.

Schaller, C. W. 1955. Inheritance of resistance to net blotch in barley. Phytopathology 45:174-176.

Scott, D. B. 1991. Identity of Pyrenophora isolates causing net-type and spot-type lesions on barley. Mycopathologia 116:29-35.

Shaikh, S. A. 2012. Measures derived from a $2 \times 2$ table for an accuracy of a diagnostic test. J. Biom. Biostat. 2:1-4.

Sharma, H. S. S. 1984. Assessment of the reaction of some spring barley cultivars to Pyrenophora teres using whole plants, detached leaves and toxin bioassay. Plant Pathol. 33:371-376.

Shipton, W. A. 1966. Effect of net blotch infection of barley on grain yield and quality. Aust. J. Exp. Agric. Anim. Husb. 6:437-440.

Shipton, W. A., Khan, T. N., and Boyd, W. J. R. 1973. Net blotch of barley. Rev. Plant Pathol. 52:269-290.

Smedegård-Petersen, V. 1974. Reduction in yield and grain size of barley due to attack by the net blotch fungus Pyrenophora teres. Pages 108-117 in Yearbook of the Royal Veterinary and Agricultural University. Royal Veterinary and Agricultural University, Copenhagen.

Steffenson, B. J., and Webster, R. K. 1992. Pathotype diversity of Pyrenophora teres f. teres on barley. Phytopathology 82:170-177.

Tekauz, A. 1985. A numerical scale to classify reactions of barley to Pyrenophora teres. Can. J. Plant Pathol. 7:181-183.

van den Berg, C. G. J., and Rossnagel, B. G. 1991. Epidemiology of spot-type net blotch on spring barley in Saskatchewan. Phytopathology 81:1446-1452.

Weiland, J. J., Steffenson, B. J., Cartwright, R. D., and Webster, R. K. 1999 Identification of molecular genetic markers in Pyrenophora teres $\mathrm{f}$. teres associated with low virulence on 'Harbin' barley. Phytopathology 89:176-181.

Xi, K., Helm, J. H., Burnett, P. A., Turkington, T. K., and Tekauz, A. 1999 Determining quantitative resistance of barley cultivars at the seedling stage to net blotch caused by Pyrenophora teres. Can. J. Plant Pathol. 21:284-290. 